University of Nebraska - Lincoln

DigitalCommons@University of Nebraska - Lincoln

Agronomy \& Horticulture -- Faculty Publications

Agronomy and Horticulture Department

2012

\title{
Local Conditions, Not Regional Gradients, Drive Demographic Variation of Giant Ragweed (Ambrosia trifida) and Common Sunflower (Helianthus annuus) Across Northern U.S. Maize Belt
}

\author{
Samuel E. Wortman \\ University of Nebraska-Lincoln, swortman@unl.edu \\ Adam Davis \\ U.S. Department of Agriculture \\ Brian J. Schutte \\ U.S. Department of Agriculture, Schutteb@msu.edu \\ John L. Lindquist \\ University of Nebraska-Lincoln, jlindquist1@unl.edu \\ John Cardina \\ Ohio State University
}

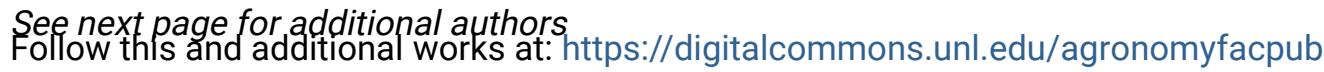

Part of the Plant Sciences Commons

Wortman, Samuel E.; Davis, Adam; Schutte, Brian J.; Lindquist, John L.; Cardina, John; Felix, Joel; Sprague, Christy L.; Dille, J. Anita; Ramirez, Analiza H. M.; Reicks, Graig; and Clay, Sharon A., "Local Conditions, Not Regional Gradients, Drive Demographic Variation of Giant Ragweed (Ambrosia trifida) and Common Sunflower (Helianthus annuus) Across Northern U.S. Maize Belt" (2012). Agronomy \& Horticulture -Faculty Publications. 624.

https://digitalcommons.unl.edu/agronomyfacpub/624

This Article is brought to you for free and open access by the Agronomy and Horticulture Department at DigitalCommons@University of Nebraska - Lincoln. It has been accepted for inclusion in Agronomy \& Horticulture -Faculty Publications by an authorized administrator of DigitalCommons@University of Nebraska - Lincoln. 


\section{Authors}

Samuel E. Wortman, Adam Davis, Brian J. Schutte, John L. Lindquist, John Cardina, Joel Felix, Christy L. Sprague, J. Anita Dille, Analiza H. M. Ramirez, Graig Reicks, and Sharon A. Clay 


\title{
Local Conditions, Not Regional Gradients, Drive Demographic Variation of Giant Ragweed (Ambrosia trifida) and Common Sunflower (Helianthus annuus) Across Northern U.S. Maize Belt
}

\author{
Sam E. Wortman, Adam S. Davis, Brian J. Schutte, John L. Lindquist, John Cardina, Joel Felix, Christy L. Sprague, \\ J. Anita Dille, Analiza H. M. Ramirez, Graig Reicks, and Sharon A. Clay*
}

\begin{abstract}
Knowledge of environmental factors influencing demography of weed species will improve understanding of current and future weed invasions. The objective of this study was to quantify regional-scale variation in vital rates of giant ragweed and common sunflower. To accomplish this objective, a common field experiment was conducted across seven sites between 2006 and 2008 throughout the north central U.S. maize belt. Demographic parameters of both weed species were measured in intra- and interspecific competitive environments, and environmental data were collected within site-years. Site was the strongest predictor of belowground vital rates (summer and winter seed survival and seedling recruitment), indicating sensitivity to local abiotic conditions. However, biotic factors influenced aboveground vital rates (seedling survival and fecundity). Partial least squares regression (PLSR) indicated that demography of both species was most strongly influenced by thermal time and precipitation. The first PLSR components, both characterized by thermal time, explained $63.2 \%$ and $77.0 \%$ of variation in the demography of giant ragweed and common sunflower, respectively; the second PLSR components, both characterized by precipitation, explained $18.3 \%$ and $8.5 \%$ of variation, respectively. The influence of temperature and precipitation is important in understanding the population dynamics and potential distribution of these species in response to climate change.
\end{abstract}

Nomenclature: Giant ragweed, Ambrosia trifida L. AMBTR; common sunflower, Helianthus annuus L. HELAN; maize, Zea mays L.; soybean, Glycine $\max (\mathrm{L}$.$) Merr.$

Key words: Vital rates, weed demography, plant distribution, climate change, environmental clines, population dynamics.

Knowledge of weed population dynamics on a regionalscale is essential in understanding current and future weed invasions in response to climate change. The patchy but often predictable distribution of weed species commonly observed within fields suggests optimum conditions for population growth are species-specific and spatially heterogeneous (Burton et al. 2005). Several studies have measured factors potentially influencing weed population dynamics, including: crop and weed management, soil physical and chemical properties, and annual weather variability (e.g., Cousens and Mortimer 1995; Dale et al. 1992; Davis et al. 2004; Dieleman et al. 2000a). Keddy (1992) suggested that environmental factors act as filters, eventually removing from local communities those species that lack the traits necessary for success. If identified, these filters and subsequent plant associations may provide valuable information about the biology of the species and the specific locations where they can be found (Dieleman et al. 2000b).

Much of the research on weed demography and distribution has been focused on identifying physical, chemical, and biological sources of field-scale variability (Burton et al. 2005; Davis et al. 2005; Dieleman et al. 2000a,b; Forcella 1992;

\footnotetext{
DOI: 10.1614/WS-D-11-00196.1

*First and fourth authors: Graduate Research Assistant and Professor, Department of Agronomy and Horticulture, University of Nebraska-Lincoln, Lincoln, NE 68583-0915; second and third authors: Research Ecologists, U.S. Department of Agriculture-Agricultural Research Service Global Change and Photosynthesis Research Unit, 1102 South Goodwin Avenue, Urbana, IL 61801; fifth and sixth authors: Professor and Postdoctoral Research Associate, Ohio State University, OARDC-Wooster, 116 Gourley Hall, Wooster, OH 44691; seventh author: Associate Professor, Department of Crop and Soil Sciences, Michigan State University, A466 Plant and Soil Sciences Building, East Lansing, MI 48824, eighth and ninth authors: Associate Professor and Graduate Research Assistant, Department of Agronomy, Kansas State University, 2004 Throckmorton Plant Sciences Center, Manhattan, KS 66506; tenth and eleventh authors: Research Assistant and Professor, Department of Plant Science, South Dakota State University, Agricultural Hall Box 2207A, Brookings, SD 57007. Corresponding author's E-mail: sam.wortman@huskers.unl.edu
}

Forcella et al. 1992; Schafer and Kotanen 2003). Despite the often strong relationship between these environmental factors and weed demography within years, there is often variation among years and sites that cannot be sufficiently explained by field-scale differences in soil and elevation. Additional influences on plant demography may include weather variables like precipitation and temperature (Mack and Pyke 1983; Wang and Gao 2003). For many weed species, increasing temperature accelerates germination but can also lead to seed decay; thus, increasing temperature generally decreases seedbank persistence (Davis et al. 2005; Schafer and Kotanen 2003). Overall, the fate of weed seeds in the soil environment is likely to be dependent on temperature and precipitation. These two factors often follow geographical gradients within regions and may account for some variation in plant demography.

Regional environmental clines have been shown to affect a wide variety of biological responses. Spatial trends in biological distribution, specifically with regard to geography and climate, have been observed for both plant and animal species in agriculture for decades (Hopkins 1919). In plants, biogeographical clines can lead to gradients of varying plant performance, morphology, phenotypic traits, and life history characteristics (Colautti et al. 2009; Keller et al. 1999). Of these biogeographical variables, latitude and altitude are often effective in explaining heterogeneity in plant performance (Ehleringer 1988; Keller et al. 1999; Savolainen et al. 2007). However, other studies have shown that latitude is not always well correlated with plant performance (Gaston 2009). Despite the potential influence of biogeographical clines on plant performance, site characteristics associated with individual locales may sometimes be a more effective predictor of plant demography and distribution (Woodward 1987).

Many studies have suggested that site and site properties can be used as effective predictors of plant distribution and performance (e.g., Byers and Quinn 1998; Davis et al. 2005; 
Santamaria et al. 2003). Typically, a "site" is limited in size to include an area relatively homogenous in climatic and edaphic properties (e.g., one farmer field). The properties associated with a given site are often highly correlated, especially with regard to their effects on plant performance; thus, it would seem site may often be sufficient to characterize current and future weed distributions (Andreasen et al. 1991; Byers and Quinn 1998; Dale et al. 1992; Dieleman et al. 2000a). Davis et al. (2005) found that the site effect explained 70 to $90 \%$ of the variation in common lambsquarters (Chenopodium album L.) and velvetleaf (Abutilon theophrasti Medik.) seedbank persistence, which is significantly more than associated measures of soil hydrothermal time (8 to $18 \%)$. Despite the demonstrated effects of site, interannual variability within and among sites can limit the importance of site properties in predicting plant distribution and performance. For example, Mack and Pyke (1983) found that site was not an effective predictor of weed demography largely due to abnormal annual precipitation patterns within sites. The effectiveness of site as a predictor of weed performance is likely most successful when comparing several extreme environments over long periods of time (Diaz et al. 1998).

Despite the challenges of understanding weed population dynamics across a region, it is becoming an increasingly relevant area of research because of species migrations associated with global climate change (Pearson et al. 2002). Observed and predicted trends in climate change include a latitudinal shift of local climates toward the poles (Walther et al. 2002). Because climate has been shown to influence plant species distribution, it is expected that species will follow these locally adapted climates toward the poles to the extent that dispersal and resource availability allow. Indeed, there is a growing body of evidence suggesting that the distribution of plant species has already shifted after only 30 years of observed warming (Walther et al. 2002). As warming trends continue, it is essential to understand the complex factors responsible for variation in the demography of dominant weed species. One of the most common approaches to understanding current and future weed distribution is through the use of static correlative statistical models relating environmental factors to plant performance and distribution (Pearson et al. 2002).

The aim of this study was to assess the relative importance of site (e.g., soil properties, elevation, latitude, and longitude), year (interannual weather variability), and competitive environment on the variation in vital rates of giant ragweed (AMBTR) and common sunflower (HELAN), two economically important weed species (Bauer and Mortensen 1992; Harrison et al. 2001). We conducted a regional-scale field experiment to accomplish two objectives: (1) quantify the sources and magnitude of regional-scale variation in the vital rates of AMBTR and HELAN over multiple site-years in the north central region of the United States; and (2) measure weather variables at each of the sites and relate these factors to variation in vital rates. Our objectives were framed by the following hypotheses. First, belowground vital rates (overwinter seed survival, oversummer seed survival, and seedling recruitment) will be most influenced by site and year, while aboveground vital rates (seedling survival to reproductive maturity and fecundity) will be most influenced by site and crop environment; more specifically, we predicted that values for aboveground vital rates will be reduced in the interspecific competitive crop environment compared to the intraspecific bare fallow environment. Second, regional-scale variation in the vital rates of AMBTR and HELAN will be driven in part by variation in temperature and precipitation. Finally, we hypothesized that values for demographic indicators of AMBTR performance will increase from west to east, whereas values for indicators of HELAN performance will increase from east to west, consistent with the distribution of historically abundant weedy populations and the longitudinal gradient of increasing annual precipitation (west to east) in the north central U.S. maize belt (Bridges and Baumann 1992).

\section{Materials and Methods}

Experimental Sites. In order to quantify variation in demographic parameters across the north central United States, a common experimental protocol was established at seven university research farms in six states over 2 or 3 years. The north central United States offers a longitudinal gradient of average annual precipitation and a latitudinal gradient of average annual temperature necessary for accomplishing study objectives (Figure 1). Study sites included: Savoy, IL (latitude $40.05^{\circ}$, longitude $-88.24^{\circ}$ ), East Lansing, MI (latitude $42.71^{\circ}$, longitude $-84.47^{\circ}$ ), St. Charles, MI (latitude $43.34^{\circ}$, longitude $-84.13^{\circ}$ ), Manhattan, KS (latitude $39.12^{\circ}$, longitude $-96.64^{\circ}$ ), Ithaca, NE (latitude $41.17^{\circ}$, longitude $-96.41^{\circ}$ ), Aurora, SD (latitude $44.29^{\circ}$, longitude $-96.65^{\circ}$ ), and Wooster, $\mathrm{OH}$ (latitude $40.78^{\circ}$, longitude $-81.92^{\circ}$ ). Soil series and classification, \% organic carbon, and $\mathrm{pH}$ for each site are presented in Table 1. AMBTR was tested at all seven sites in 2007 and 2008, whereas HELAN was tested at six sites in 2007 and 2008; HELAN was omitted from the Ohio site in all years due to labor constraints. AMBTR and HELAN were tested only at the Illinois and two Michigan sites in 2006 to collect preliminary data.

Study Design. Demographic parameters were measured in maize and fallow environments that were established in adjacent plots $(10.28$ by $9.12 \mathrm{~m})$ within agricultural fields following soybean phases of maize-soybean rotations. Experimental areas were chisel-plowed each fall following soybean harvest. Both maize and fallow plots within a site-year received identical preplant burndown applications of various herbicides (depending on site-year) without residual soil activity at rates sufficient for weed-free starts at planting in 2007 and 2008 but not in 2006. This practice was implemented in 2007 and 2008 to facilitate planting operations and to more accurately mimic conventional maize management practices in the north central United States. In 2006, weed communities accumulated throughout the growing season without herbicide application prior to planting maize. However, in 2007 and 2008, the preplant herbicide application eliminated early-season weed cohorts. It was possible to observe emergence of AMBTR and HELAN both before and after the preplant herbicide application, but in some site-years no individuals emerged following this application. Thus, estimates of seedling survival to reproductive maturity were inflated in 2006, relative to 2007 and 2008. However, the other four vital rates observed in this study should have been uninfluenced by this change in experimental protocol. Maize was planted in appropriate plots at a target population of 74,000 plants $\mathrm{ha}^{-1}$ using locally adapted hybrids in rows spaced $76 \mathrm{~cm}$ apart. Planting typically occurred between late April and early May across all 

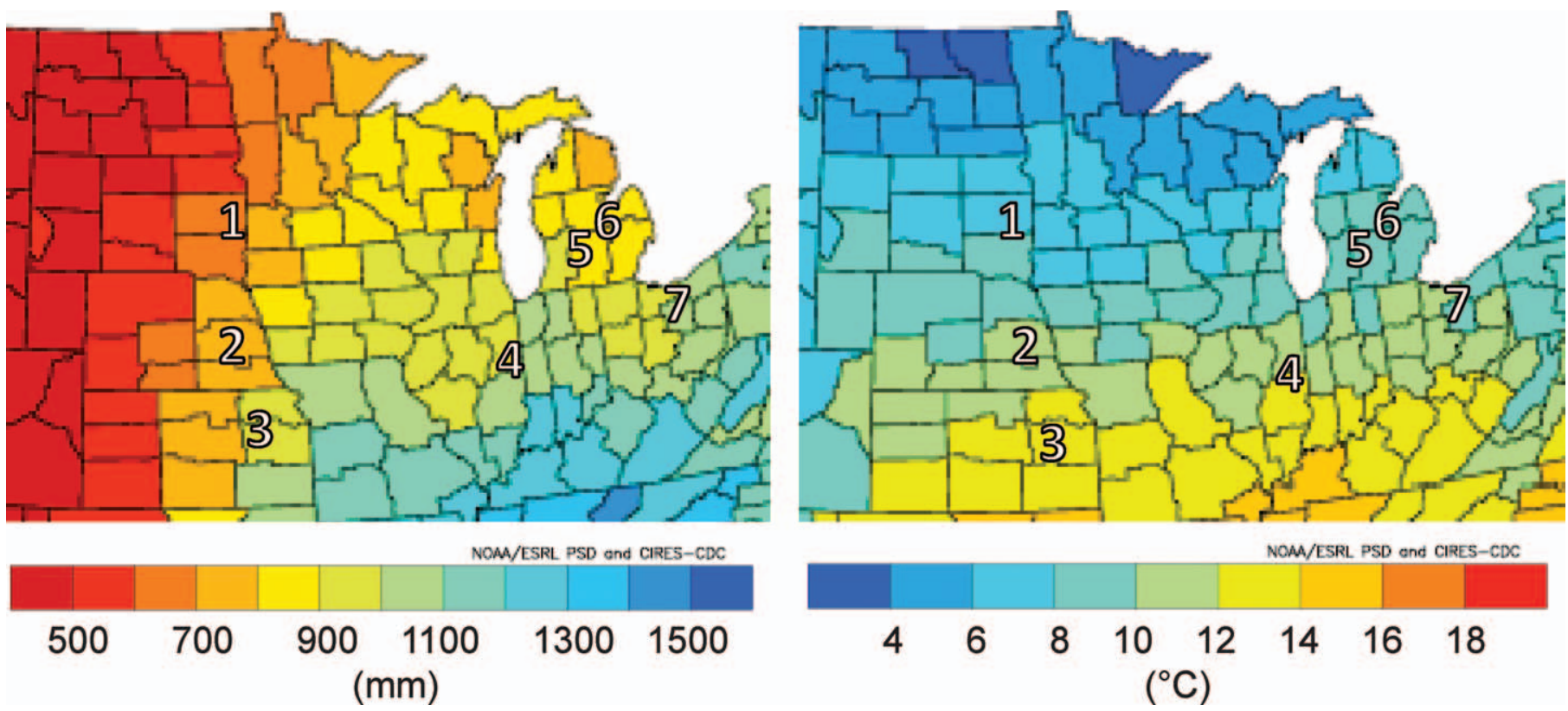



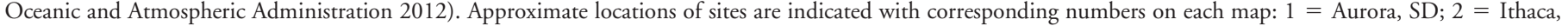
NE; 3 = Manhattan, KS; 4 = Savoy, IL; 5 = East Lansing, MI; 6 = St. Charles, MI; and $7=$ Wooster, OH.

site-years. At 2 to 4 wk after planting, maize and fallow plots were fertilized with granular ammonium nitrate or urea fertilizer at locally recommended rates for optimal maize growth. Throughout the growing season, study sites were kept free of unwanted vegetation with various herbicides (depending on site) and hand-weeding.

The experimental design was a nested hierarchical design with the following structure: year\{site\{weed species\{crop environment $\}\}$. However, within a given site-year, individual field experiments were designed as randomized complete block with four replications. Experimental units comprised two adjacent quadrats $(1.32$ by $0.76 \mathrm{~m})$ designated to either belowground demographic parameters (overwinter seed survival, oversummer seed survival, and seedling recruitment) or aboveground demographic parameters (seedling survival to reproductive maturity and fecundity). For each experimental unit, starting ambient densities of viable AMBTR and HELAN seeds were determined by excavating soil blocks $(12.5$ by $12.5 \mathrm{~cm}$ by $5 \mathrm{~cm}$ depth) and recovering seeds with mechanical elutriation (Wiles et al. 1996). Recovered seeds were subjected to tetrazolium assays using 1\% (v/v) aqueous solutions of 2,3,5-triphenyl-tetrazolium chloride to determine viability (Peters 2000). Seed survival and seedling recruitment data were adjusted for ambient densities of each weed species.

Seed Burial and Measurement of Demographic Parameters. Common seed lots were used across sites for both AMBTR (collected near Dekalb, IL; latitude 41.929 ${ }^{\circ}$, longitude $-88.740^{\circ}$ ) and HELAN (collected near Manhattan, KS; latitude $39.183^{\circ}$, longitude $-96.572^{\circ}$ ). Common seed lots were utilized to eliminate variation expected among local weed biotypes, shifting the study focus solely on the role of environmental variation on weed species demography. Seeds were buried between October 1 and December 1 of the same year of collection. Demographic parameters $S w$ (the proportion of buried seed surviving winter) and $S s$ (the proportion of buried seed surviving summer) were determined through burial-and-recovery of seed batches $\left(100\right.$ seeds batch $\left.{ }^{-1}\right)$ buried $2.5 \mathrm{~cm}$ within trays $(12.5$ by $12.5 \mathrm{~cm}, 6 \mathrm{~cm}$ depth) that were fabricated from $1-\mathrm{mm}^{2}$ wire mesh screen and incorporated in soil to a depth of $5 \mathrm{~cm}$. As discussed above, recovery of buried seeds was accomplished with mechanical elutriation, and viability of recovered seeds was determined with tetrazolium assays. $S w$ and $S s$ were calculated as:

$$
S w(\text { or } S s)=R /([B+A]-[G])
$$

where $R=$ number of recovered viable seeds in March (or the following October), $B=$ number of viable seeds buried in October, $A=$ number of viable ambient seeds, and $G=$ number of seeds emerged. Seed batches for $S s$ were also used in the determination of demographic parameter $G$ (the proportion of buried seed producing a seedling) by counting and removing seedlings from mesh trays at 7-d intervals beginning late March and continuing until emergence was no

Table 1. Soil series, classification, percent organic carbon (\% OC), and $\mathrm{pH}$ for the seven experimental sites in the north central region, United States.

\begin{tabular}{|c|c|c|c|c|}
\hline Location & Soil series & Soil classification & \% Soil OC & Soil pH \\
\hline Savoy, IL & Catlin silt loam & fine-silty, mixed, mesic Oxyaquic Argiudoll & 4.2 & 7.2 \\
\hline East Lansing, MI & Capac fine sandy loam & fine-loamy, mixed, mesic Aquic Glossudalfs & 2.5 & 6.9 \\
\hline St. Charles, MI & Zilwaukee silty clay & fine, mixed, mesic Fluvaquentic Endoaquolls & 3.9 & 7.4 \\
\hline Manhattan, KS & Wymore silty clay loam & fine, smectitic, mesic Aquertic Argiudolls & 2.5 & 5.9 \\
\hline Ithaca, NE & Sharpsburg silty clay loam & fine, smectitic, mesic Typic Argiudoll & 3.3 & 6.1 \\
\hline Aurora, SD & Brandt silty clay loam & fine-silty, mixed, frigid Calcic Hapludoll & 3.5 & 6.5 \\
\hline Wooster, OH & Wooster loam & fine, mixed, Typic Fragiaqualf & 2.9 & 6.5 \\
\hline
\end{tabular}


longer observed. $G$ was calculated as:

$$
G=E /(B+A)
$$

where $E=$ number of emerged seedlings, $B=$ number of viable seeds buried in October, and $A=$ number of viable ambient seeds.

Seed enrichment zones were established in aboveground quadrats by spreading 100 seeds evenly across the $1-\mathrm{m}^{2}$ area of appropriate plots and mixing these seeds to a depth of $2.5 \mathrm{~cm}$ using landscape rakes. These seed enrichment zones were surveyed for emerged plants at weekly intervals beginning late March and continuing throughout the summer. Emerged plants were counted but not removed. In August, reproductively mature individuals in seed enrichment zones were counted. The demographic parameter SSDL (the proportion of seedlings surviving to reproductive maturity) was calculated as:

$$
S S D L=(F / E)
$$

where $F=$ number of reproductive individuals, and $E=$ number of emerged seedlings. At seed maturity but prior to seed dispersal, all reproductively mature plants within the $1-\mathrm{m}^{2}$ aboveground quadrats were clipped at the soil surface, bagged, and oven-dried. Seeds were harvested from a subset of reproductively mature plants representative of the range in plant biomass, and regressions for response of seed output to increasing oven-dry plant biomass were used to determine seed output for all reproductively mature plants of a given site-year, providing an estimate of the demographic parameter $F$ (seed output plant ${ }^{-1}$ ).

Environmental Variables. For each site-year, data were collected for the following environmental variables: latitude, longitude, elevation, daily total precipitation, and daily minimum and maximum temperatures. These data were used to derive daily growing degree units based on several temperature thresholds (base $2 \mathrm{C}, 3.2 \mathrm{C}, 4.4 \mathrm{C}$, and $10 \mathrm{C}$ ) previously reported for weed emergence and growth (WeedCast, version 4, North Central Soil Conservation Research Laboratory, U.S. Department of Agriculture-Agricultural Research Service, Morris, MN; Schutte et al. 2008). Daily weather data were summarized across five specific time periods that corresponded to specific demographic parameters or calendar breaks including: winter seed survival, summer seed survival, seedling recruitment, weed growth, and the entire calendar year. Time periods for winter and summer seed survival were similar across site-years, with the winter seed survival period typically running from October 1 through March 31 and the summer seed survival period typically running from April 1 to September 30. Periods for seedling recruitment and weed growth were dependent on the timings of these life-stage transitions in particular site-years. The following environmental factors were calculated within each of these specific time periods: mean daily average air temperature ([maximum temperature + minimum temperature]/2), standard deviation of mean daily average air temperature, cumulative growing degree days (GDDs) base $2 \mathrm{C}\left(\mathrm{GDD}_{2}\right.$; cumulative GDDs base 3.2 C, $4.4 \mathrm{C}$, and $10 \mathrm{C}$ were eliminated in favor of base $2 \mathrm{C}$ after preliminary data reduction step using PLSR analysis), total precipitation, and number of rain days. These environmental factors are considered essential to the physiological success of herbaceous weedy species and have been used in the development of several bioclimatic models of plant distribution (e.g., Pearson et al. 2002; Pearson and Dawson 2003; Thuiller 2003). Daily average air temperature and total precipitation data for winter (October 1 to March 31) and summer (April 1 to September 30) periods for all site-years are reported in Table 2.

GDDs were calculated continuously throughout the calendar year and used as an environmental predictor variable for each of the five time periods outlined above. Thus, the GDD "clock" was reset at the beginning of each specified time period. For $S w$, GDDs accumulated beginning the day after fall seed burial until the day of seed recovery in the spring. Similarly, GDDs for $S s$ began accumulating $1 \mathrm{~d}$ after spring seed recovery and concluded on the day of fall seed recovery. The specific dates for seed burial and recovery varied among site-years. In the case of seedling recruitment $(G)$, GDDs accumulated beginning on the day of first weed seedling emergence and concluded on the day of last weed seedling emergence specific to each site-year. Lastly, GDDs during weed growth (the $S S D L$ life-stage transition) accumulated from the time of preplant burndown herbicide application (2007 and 2008) until the time of weed harvest. GDDs for the $S S D L$ life stage transition began accumulating $1 \mathrm{~d}$ following the last weed seedling emergence in 2006. GDDs for each of the previous four time periods were summed to determine GDDs for the entire calendar year.

Data Analysis. Linear mixed model analyses were conducted using PROC MIXED in SAS 9.2 (SAS Institute, Inc., Cary, $\mathrm{NC)}$ to accomplish objective 1 and determine the effect of site, year, and crop on each demographic parameter. Fixed effects in the model included crop, site, year, and all possible interactions of these factors, while the random effect in the model was replication nested within year. However, the model to test for effects on $S w$ excluded the crop effect and all interactions with crop, as $S w$ should be unaffected by the presence of a crop in the subsequent growing season. Prior to analysis, all proportion data $(S s, S w, G$, and $S S D L)$ were $\operatorname{arcsine}(x)^{0.5}$-transformed (Hogg and Craig 1995), while data for $F$ was $\log$-transformed to correct for overdispersed residuals. Mean data for site-crop-years was used for subsequent multivariate analysis to avoid pseudo-replication of environmental data within sites. As a complementary approach to addressing the first objective, we constructed a fully random hierarchical linear mixed model using the lmex library of the open source statistical software program $\mathrm{R}$ v.2.10.1 (R Foundation for Statistical Computing, http:// www.r-project.org). This analysis identified spatial (site), temporal (year), and biological (crop environment) contributions to the variance. Variance in individual demographic parameters for both weed species was partitioned into orthogonal components according to the nested hierarchical experimental design by year, year $\{$ site $\}$, year $\{$ site $\{c r o p\}\}$, and pure error (Gotelli and Ellison 2004).

For each demographic parameter and their corresponding time period, there were a total of nine measured environmental predictor variables: latitude, longitude, elevation, mean daily air temperature, standard deviation of mean daily air temperature, cumulative $\mathrm{GDD}_{2}$, precipitation, number of rain days, and actual length of the specific period (i.e., summer, winter, seedling recruitment period, weed growth). There were strong correlations among these environmental variables and also among the individual demographic 


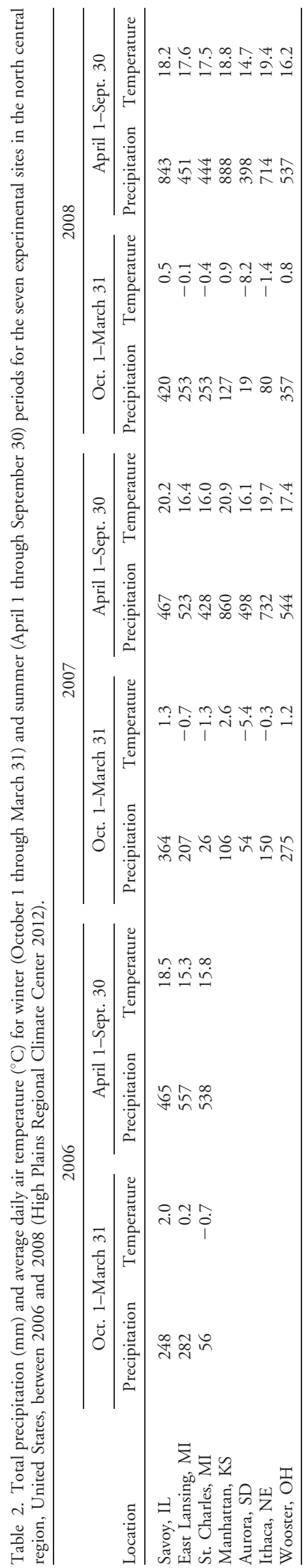

parameters indicating multicollinearity in the data (data not shown). Environmental factors do not act independently on plant traits, which make a posteriori partitioning of variance in demographic parameters difficult when using traditional univariate statistical methods. Moreover, this data set included a large number of predictor variables and a relatively small number of mean observations for each weed species; thus, PLSR (a multivariate statistical method) analyses were conducted to accomplish objective 2 using the pls library of the open source statistical software program R v.2.12.1.

PLSR is an extension of multiple regression analysis where the relationship between predictor and response variables are determined with latent variables, which are defined as linear combinations between predictor and response variables. The relationship between the latent variables and response variables can then be interpreted similar to regression coefficients and the response variable in multiple regression (Carrascal et al. 2009). While lambda (population growth rate) is often used as an integrative measure of demographic success, the use of PLSR is advantageous in this case because the analysis provides insight about contributions from individual demographic parameters through interpretation of the latent variable loadings (Horvitz and Schemske 1995). A training set (two-thirds of the data set) and test set (onethird of the data set) were used to establish and validate PLSR models for both AMBTR and HELAN. The number of components used in the PLSR models was determined by selecting $>80 \%$ as an acceptable explained variance threshold; thus, two components were included in the PLSR model for each species.

\section{Results and Discussion}

Giant Ragweed Demographic Parameters. Between 2006 and 2008, winter seed survival $(S w)$ of AMBTR was influenced by the site* year interaction (Table 3), and $S w$ ranged from $14 \%$ at St. Charles, MI, in 2006 to $87 \%$ at Manhattan, KS, in 2008 (Figure 2). Summer seed survival $(S s)$ of AMBTR was also influenced by the site*year interaction and ranged from $0.8 \%$ at St. Charles, MI, in 2008 to $85 \%$ at Aurora, SD, in 2008 (Figure 2). The range of seed survival rates observed across all site-years was greater than values observed by Harrison et al. (2007), who found AMBTR seed survival ranged from 0 to $34 \%$ after $1 \mathrm{yr}$ depending on seed size and burial depth. Although AMBTR is historically more common in the east and southeast portions of the north central United States (Bridges and Baumann 1992; Harrison et al. 2001), values for $S w$ and $S s$ (a portion of demographic performance) were greatest in Manhattan, KS, and Aurora, SD (in the western portion of the north central United States) across site-years. In contrast, values for $S w$ and Ss were lowest in an eastern site (St. Charles, MI) where AMBTR is historically more abundant (Bridges and Baumann 1992). Both observations are inconsistent with the expected spatial distribution of demographic performance across the region.

Seedling recruitment $(G)$ of AMBTR was influenced by the site $^{*}$ year and year ${ }^{*}$ crop interactions ranging from $6 \%$ at Savoy, IL, in 2007 to $45 \%$ at Wooster, OH, in 2008 (Figure 2). Similarly, Harrison et al. (2007) reported seedling recruitment rates ranging from 19 to $49 \%$ depending on seed size and burial depth. The year*crop interaction was the result 
Table 3. Results of $F$-tests for fixed effects in linear mixed effects models of demographic parameters for Ambrosia trifida across the north central region, United States. Demographic parameters include: $S w=$ winter seed survival; $S s=$ summer seed survival; $G=$ seedling recruitment; $S S D L=$ seedling survival to reproductive maturity; and $F=$ fecundity.

\begin{tabular}{|c|c|c|c|c|c|}
\hline \multirow[b]{2}{*}{ Effect } & \multicolumn{5}{|c|}{ Demographic Parameter } \\
\hline & $S w$ & Ss & $G$ & $S S D L$ & $F$ \\
\hline & & & -P-value & & \\
\hline Site & $<0.0001$ & $<0.0001$ & $<0.0001$ & $<0.0001$ & $<0.0001$ \\
\hline Crop & & 0.0641 & 0.0566 & 0.0142 & 0.0214 \\
\hline Site* crop & & 0.1642 & 0.5072 & $<0.0001$ & 0.0876 \\
\hline Year & $<0.0001$ & 0.0294 & 0.0002 & 0.0002 & 0.0155 \\
\hline Site* year & $<0.0001$ & $<0.0001$ & $<0.0001$ & $<0.0001$ & $<0.0001$ \\
\hline Year*crop & & 0.6892 & 0.0032 & 0.0043 & 0.0004 \\
\hline Site* $^{*}{ }^{*}{ }^{*}$ crop & & 0.2258 & 0.1902 & 0.0253 & $<0.0001$ \\
\hline
\end{tabular}

of increased values for $G$ in the bare fallow environment in 2007 but not 2006 or 2008 . Warmer soil temperatures in a bare fallow environment without a dense crop canopy may have contributed to increased values for $G$ in 2007 relative to the maize environment. While $G$ was affected by site-year characteristics, the apparent influence of crop environment on this belowground demographic parameter is contradictory to the prediction in hypothesis 1. SSDL of AMBTR was influenced by the site*year*crop interaction (Table 3) and ranged from $0 \%$ in the bare fallow environment at Ithaca, $\mathrm{NE}$, in 2007 to $100 \%$ in the bare fallow environment at Wooster, $\mathrm{OH}$, in 2007 (Figure 2). The interaction was the result of high values for SSDL at four site-years (Savoy, IL, 2007 and 2008; St. Charles, MI, 2007 and 2008) in the bare fallow habitat and a low value for SSDL in one site-year (Ithaca, NE, 2007) in the bare fallow habitat, whereas the remaining site-years were generally unaffected by the competitive environment (Figure 2). While the crop environment did influence values for $S S D L$, the direction of the response was not always consistent with our prediction that values for $S S D L$ would decrease in the interspecific competitive environment (maize habitat).

Fecundity $(F)$ of AMBTR was influenced by the interaction of site ${ }^{*}$ year*crop (Table 3 ) and $F$ ranged from 0 seeds plant ${ }^{-1}$ in the bare fallow habitat at St. Charles, MI, in 2008 to 8,227 seeds plant ${ }^{-1}$ in the bare fallow habitat at East Lansing, MI, in 2007 (Figure 2). Harrison et al. (2001) reported maximum AMBTR fecundity in maize to be 3,500 seeds $\mathrm{m}^{-2}$, while Baysinger and Sims (1991) reported fecundity as high as 7,979 seeds $\mathrm{m}^{-2}$ in soybean. As expected, $F$ varied by site-year and was generally greater in the bare fallow compared to the maize habitat. The interspecific competition occurring between maize and individual weed species has been shown to reduce vegetative and reproductive biomass that contribute to weed fecundity (Wortman et al. 2011).

Common Sunflower Demographic Parameters. Between 2006 and 2008, winter seed survival (Sw) of HELAN was influenced by the site*year interaction (Table 4) and ranged from $11 \%$ at Ithaca, NE, in 2007 to $91 \%$ at Manhattan, KS, in 2008 (Figure 3). Similarly, summer seed survival $(S s)$ of HELAN was influenced by the site*year interaction and ranged from $4 \%$ at Ithaca, NE, in 2007 to $89 \%$ at Aurora, SD, in 2008 (Figure 3). Mean rate of seed survival across siteyears (52\% combined mean for $S w$ and $S s)$ was slightly greater than the predicted values provided by Bauer and Mortensen (1992), who estimated a 40\% HELAN seedbank survival rate


Figure 2. Measured demographic parameters for AMBTR across 34 site-year-crop combinations for each experimental replication (there are four replications per siteyear-crop). Symbols and demographic parameters include: $(+)=$ maize; $(0)=$ bare soil; $S w=$ winter seed survival; $S s=$ summer seed survival; $G=$ seedling recruitment; $S S D L=$ seedling survival to reproductive maturity; $F=$ fecundity. Site abbreviations include: $\mathrm{OH}=$ Wooster, OH; MI1 = St. Charles, MI; IL = Savoy, IL; KS = Manhattan, KS; NE = Ithaca, NE; MI2 = East Lansing, MI; and SD = Aurora, SD. 
Table 4. Results of $F$-tests for fixed effects in linear mixed effects models of demographic parameters for Helianthus annuus across the north central region, United States. Demographic parameters include: $S w=$ winter seed survival; $S_{s}=$ summer seed survival; $G=$ seedling recruitment; $S S D L=$ seedling survival to reproductive maturity; and $F=$ fecundity.

\begin{tabular}{|c|c|c|c|c|c|}
\hline \multirow[b]{2}{*}{ Effect } & \multicolumn{5}{|c|}{ Demographic Parameter } \\
\hline & $S w$ & Ss & $G$ & $S S D L$ & $F$ \\
\hline & & & $-P$-value & & \\
\hline Site & $<0.0001$ & $<0.0001$ & $<0.0001$ & $<0.0001$ & $<0.0001$ \\
\hline Crop & & 0.8621 & 0.5519 & 0.0990 & 0.0783 \\
\hline Site* crop & & 0.6174 & 0.5409 & 0.0809 & 0.0029 \\
\hline Year & $<0.0001$ & 0.0048 & 0.0070 & $<0.0001$ & 0.0007 \\
\hline Site*year & $<0.0001$ & $<0.0001$ & $<0.0001$ & $<0.0001$ & $<0.0001$ \\
\hline Year*crop & & 0.2307 & 0.9117 & 0.9986 & 0.0102 \\
\hline Site* year* $^{*}$ crop & & 0.1366 & 0.2235 & 0.0005 & 0.0012 \\
\hline
\end{tabular}

based on seedbank longevity and the physical and chemical makeup of the seedcoat.

Seedling recruitment $(G)$ of HELAN was influenced by the site*year interaction and ranged from $7 \%$ at East Lansing, MI, in 2006 to 57\% at Savoy, IL, in 2006 (Figure 3). Forcella et al. (1997) reported a 5\% mean rate of HELAN seedbank emergence across 22 site-years in the central United States, which is substantially lower than the mean rate of $30 \%$ seedling recruitment observed across 15 site-years in this study. Seedling survival to reproductive maturity $(S S D L)$ of HELAN was influenced by the site ${ }^{*}$ ear ${ }^{*}$ crop interaction (Table 4), and SSDL ranged from $0 \%$ in the maize habitat at East Lansing, MI, in 2007 and in the bare fallow habitat at St. Charles, MI, in 2007 to $95 \%$ at East Lansing, MI, in 2006 in the bare fallow habitat (Figure 3). The upper and lower range for SSDL highlights the change in experimental protocol between 2006 and 2007. In 2006, a burndown herbicide was not applied prior to planting, as was the case in 2007 and 2008. Therefore, if no new weedy individuals emerged after the burndown application then $S S D L$ rates were calculated as zero (zero seedling recruits survived to reproductive maturity). Thus, the lower values for SSDL in 2007 and 2008 compared to the rates in 2006 can be attributed to the inclusion of a preplant burndown herbicide application.

$F$ of HELAN was also influenced by the interaction of site $^{*}$ year*crop (Table 4). $F$ ranged from 0 seeds plant ${ }^{-1}$ in the maize habitat at East Lansing, MI, in 2007 and in the bare fallow habitat at St. Charles, MI, in 2007 to 80,017 seeds plant $^{-1}$ in the bare fallow habitat at St. Charles, MI, in 2008 (Figure 3). Snow et al. (2003) reported a much lower range of HELAN fecundity of approximately 400 to 2,000 seeds plant $^{-1}$ in Nebraska and Colorado. Bauer and Mortensen (1992) reported that the expected fecundity of HELAN in competition with soybean is approximately 7,750 seeds plant $^{-1}$, which is more consistent with the results of this study where mean fecundity for both crop and fallow environments across 15 site-years was 9,900 seeds plant ${ }^{-1}$. In competition with maize, fecundity of HELAN was lower (5,334 seeds plant $\left.^{-1}\right)$ than when grown in the fallow environment $(14,466$ seeds plant $\left.{ }^{-1}\right)$. The higher $F$ observed here compared to the results of Snow et al. (2003) may be due to inherent differences in the fertility of the growing environment. The observations of Snow et al. (2003) were based on sunflower populations growing near roadways compared to the relatively fertile cropping environments utilized in this study. The
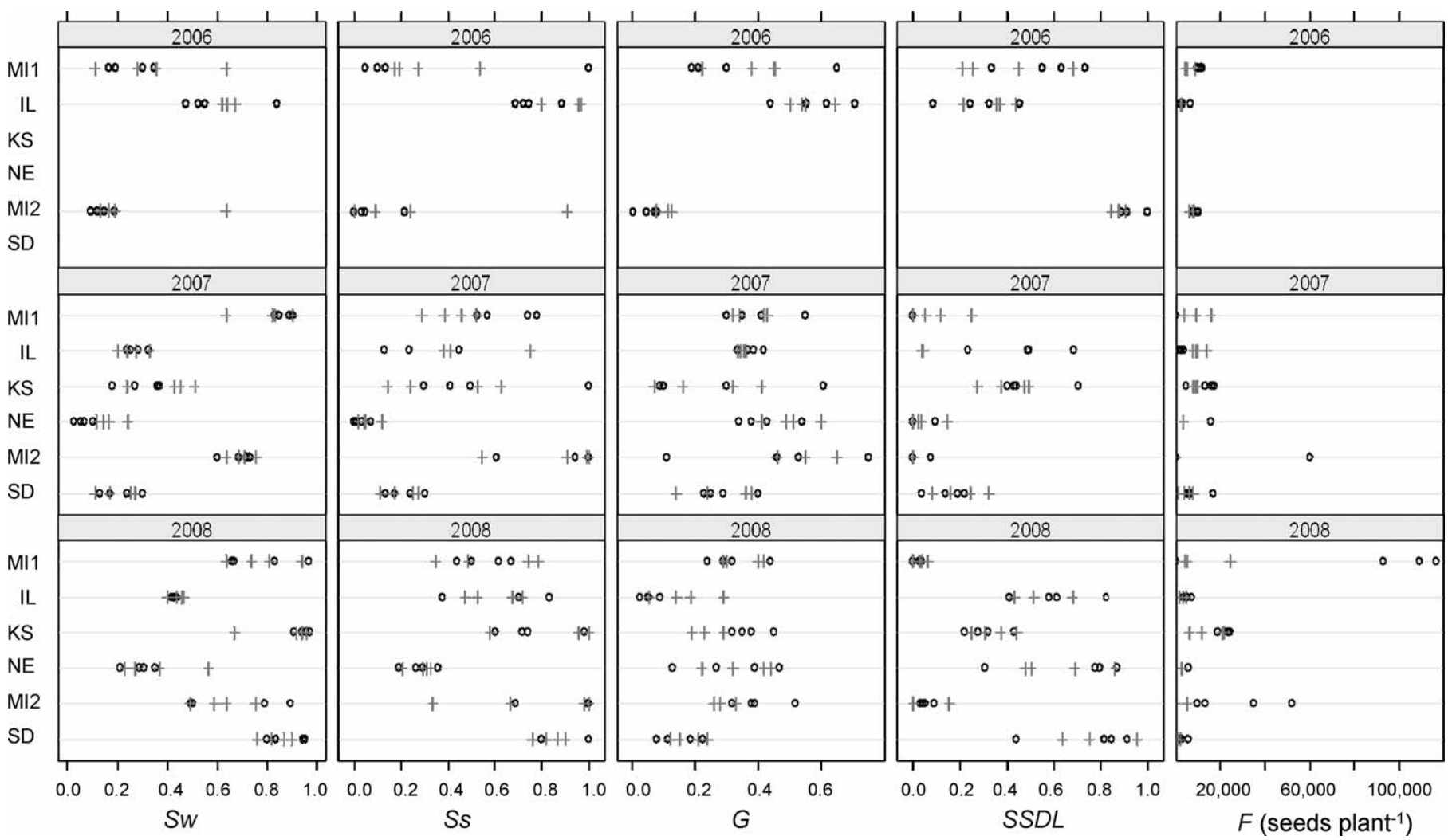

Figure 3. Measured demographic parameters for HELAN across 30 site-year-crop combinations for each experimental replication (there are four replications per siteyear-crop). Symbols and demographic parameters include: $(+)=$ maize; $(\mathrm{o})=$ bare soil; $S w=$ winter seed survival; $S s=$ summer seed survival; $G=$ seedling recruitment; $S S D L=$ seedling survival to reproductive maturity; $F=$ fecundity. Site abbreviations include: MI1 = St. Charles, MI; IL = Savoy, IL; KS = Manhattan, $\mathrm{KS} ; \mathrm{NE}=$ Ithaca, NE; MI2 = East Lansing, MI; and SD = Aurora, SD. 

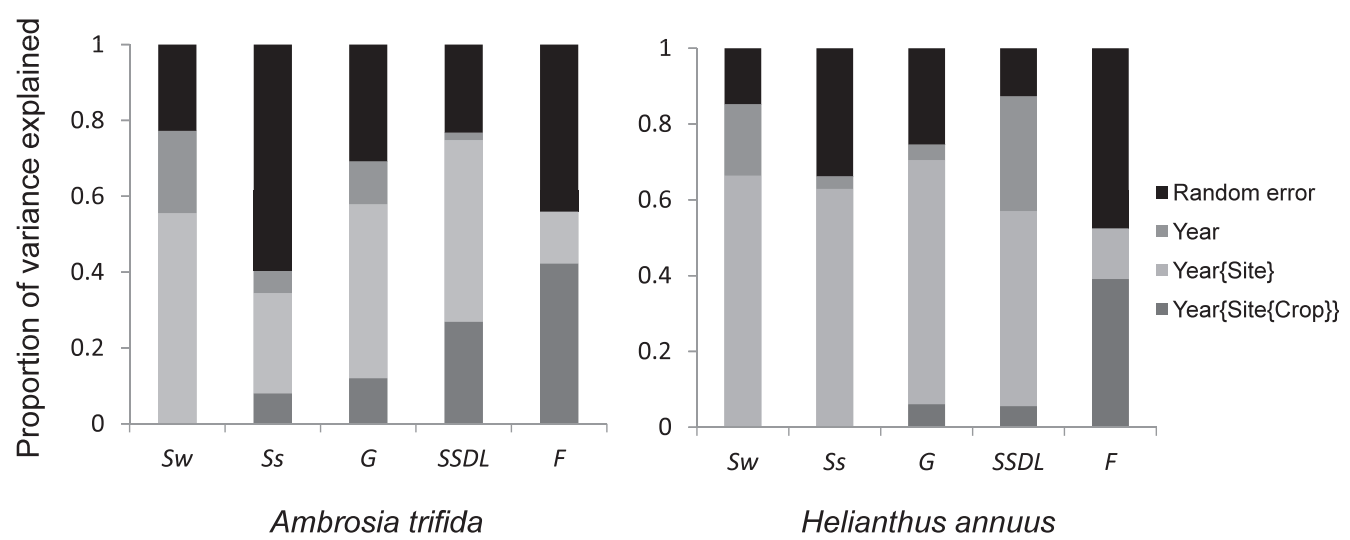

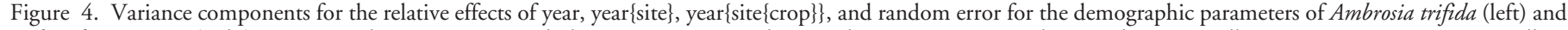

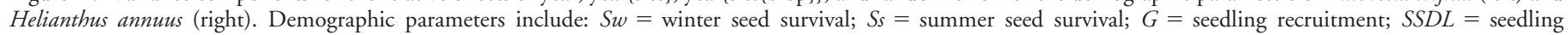
survival to reproductive maturity; and $F=$ fecundity.

interaction of site* year* crop was the result of greater $F$ rates in most but not all site-years in the bare fallow environment. In some cases, greater weed density during reproductive growth stages (greater $S S D L$ ) in the bare fallow environment may have reduced fecundity (Harrison et al. 2001). However, fecundity was generally greatest in the fallow environment regardless of seedling survival and final weed density. Similar to the results for AMBTR, increased values for $F$ were attributed to the lack of interspecific competition in the bare fallow habitat. The effect of crop on the aboveground demographic parameters (SSDL and $F$ ) for both AMBTR and HELAN suggests the competitive environment is more influential than weather in later life-stage transitions, while weather factors associated with site-years explain the most variation in early life-stage transitions $(S w, S S$, and $G)$.

All individual demographic parameters for AMBTR and HELAN were influenced by the effect of site. Moreover, site was often a more important predictor variable than crop habitat or the interaction between site and crop habitat. This result is congruent with many previous studies that have successfully used site as a predictor of plant distribution and performance (Byers and Quinn 1998; Davis et al. 2005; Joshi et al. 2001; Santamaria et al. 2003). Because the climatic and environmental properties associated with individual locations are abundant, unique, and often highly correlated, site may be the most effective predictor of plant distribution (Andreasen et al. 1991; Byers and Quinn 1998; Dale et al. 1992). However, the on-going change in global climate demands an increased understanding of the complex weather factors characterizing individual sites that may be responsible for variation in the demography of dominant weed species across regions.

Variance Partitioning. Variance partitioning within individual demographic parameters and weed species provided a valuable comparison of the relative effects of year, year\{site\}, year $\{$ site $\{$ crop\}\}, and unexplained random error sources on plant performance and regional-scale distribution (Figure 4). In explaining variation in winter and summer seed survival, and seedling recruitment and survival to reproductive maturity, year\{site\} was the most important factor. This factor explained $56,26,45$, and $48 \%$ of the variation in $S w$, Ss, $G$, and SSDL for AMBTR, respectively. Similarly, the year\{site effect explained $66,63,64$, and $51 \%$ of the variation in $S w, S s, G$, and $S S D L$ for HELAN, respectively (Figure 4). The large amount of variation explained by the year\{site\} effect for these demographic parameters for both species indicates the importance of environmental factors that conditioned each site-year (e.g., crop management, precipitation, soil moisture, and temperature; Davis et al. 2005).

The effect of year\{site\{crop\}\} was less important in explaining the variation in measures of seed survival $(S s$ and $S w$ ) and seedling recruitment $(G)$ but instead helped to explain variation in seedling survival (SSDL) and especially fecundity $(F)$. Specifically, year\{site\{crop\}\} explained 27 and $6 \%$ of variation in SSDL for AMBTR and HELAN, respectively. This effect also explained 42 and $39 \%$ of variation in fecundity for AMBTR and HELAN, respectively. These results indicate the importance of the competitive environment (e.g., crop habitat) for postemergence weed performance, especially with regard to the proliferation of weed seeds. Indeed, the influence of competitive environment on weed seedling survival and fecundity has been widely demonstrated (e.g., Brainard et al. 2005; Grundy et al. 2004). Unfortunately, the apparent influence of biotic factors like competitive environment can limit the accuracy and predictive power of bioclimatic plant demographic models (Pearson and Dawson 2003).

The relative importance of biotic factors (i.e., plant competition) on plant growth and reproduction, and abiotic factors (e.g., precipitation, temperature) on seed survival and emergence highlight the difficulty of identifying one single factor contributing to overall demographic performance (Walther et al. 2002). Depending on the life stage transition of the individual weed, it will be influenced to varying degrees by any one or combination of abiotic and biotic factors. However, these results clearly indicate that the competitive environment is most important in explaining weed fecundity while the abiotic site characteristics will be most important in explaining seed and seedling life stages. Because seed survival strongly influences long-term population growth rates of annual weeds (Davis 2006; Jordan 1993), precipitation and temperature differentials may be useful in the explanation of distribution for these two species.

For both species and across demographic parameters, the unexplained random error represented a substantial portion of the variance. For AMBTR, the random error ranged from 23 to $60 \%$ across demographic parameters, and for HELAN the 


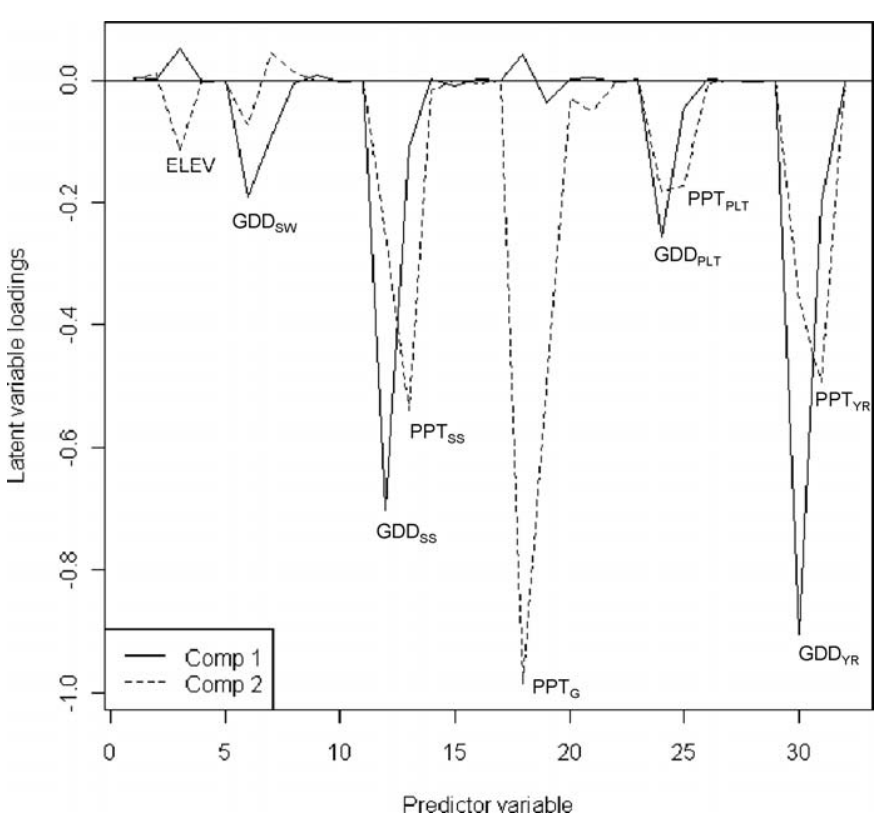

Figure 5. Latent variable loadings for 32 different environmental predictor variables in the partial least squares regression for AMBTR demography. The first component explains $63.2 \%$ of the variation in AMBTR demography, and the second component explains $18.3 \%$ of the variation. The largest latent variable loadings for each component are labeled in the figure: ELEV = site elevation; $\mathrm{GDD}_{\mathrm{SW}}=$ winter growing degree days base $2 \mathrm{C} ; \mathrm{GDD}_{\mathrm{SS}}=$ summer growing degree days base $2 \mathrm{C}$; $\mathrm{PPT}_{\mathrm{SS}}=$ summer precipitation; $\mathrm{PPT}_{\mathrm{G}}=$ precipitation during seedling recruitment; $\mathrm{GDD}_{\mathrm{PLT}}=$ growing degree days base $2 \mathrm{C}$ during weed growth; $\mathrm{PPT}_{\mathrm{PLT}}=$ precipitation during weed growth; $\mathrm{GDD}_{\mathrm{YR}}=$ annual growing degree days base $2 \mathrm{C}$; and $\mathrm{PPT}_{\mathrm{YR}}=$ annual precipitation.

random error ranged from 13 to $48 \%$ across demographic parameters (Figure 4). This portion of the variance is unknown and may represent variation attributed to replication, heterogeneity of soil characteristics within the field (Burton et al. 2004, 2005; Dieleman et al. 2000a,b), field history, or some other unknown factors. Overall, the unexplained random variance observed for individual vital rates in this study is high but not unprecedented in regional weed demography studies. Indeed, Davis et al. (2005) attributed 45 to $75 \%$ of the variance in giant foxtail (Setaria faberi Hermm.) seedbank persistence to random error. Understanding the factors responsible for demographic variation associated with each site, year, and competitive environment will provide the necessary foundation to begin exploring possible explanations for this random error.

Environmental Variation and Weed Demography. For AMBTR, demography was most affected by $\mathrm{GDD}_{2}$, as indicated by the first PLS component (a linear combination of environmental factors), which explained $63.2 \%$ of the variation in overall AMBTR demography (the linear combination of all measured demographic parameters). The most important environmental predictor variables in the first PLS component, as indicated by the largest latent variable loadings, were annual $\mathrm{GDD}_{2}, \mathrm{GDD}_{2}$ between March and October, and $\mathrm{GDD}_{2}$ during weed growth (from seedling recruitment to reproductive maturity), respectively (Figure 5). The height of each peak in Figure 5 (latent variable loadings) indicates the relative influence of individual environmental factors (contributing to the PLS component) on overall demography. The second PLS component explained $18.3 \%$ of the variation in AMBTR demography and was characterized largely by precipitation. The most important environmental predictor variables contributing to the second PLS component, as indicated by the largest latent variable loadings, were precipitation during seedling recruitment, annual precipitation, precipitation between March and October, precipitation during weed growth, and elevation, respectively (Figure 5). The direction of both PLS components was negative, indicating a negative relationship between these components and the demography of AMBTR.

These results suggest that AMBTR was most successful in site-years with a relatively low number of GDDs, typical of the northern sites in this study. To a lesser degree, demography of AMBTR was negatively related to precipitation and elevation, which suggests that AMBTR was successful in site-years with low precipitation and at sites with low elevation. This result offers strong support for hypothesis 2 as it identifies a gradient of AMBTR success explained by temperature $\left(\mathrm{GDD}_{2}\right)$ and precipitation. However, the observed climatic gradient offers limited support for hypothesis 3. The historically abundant populations of AMBTR are typically found in the east and southeast portions of the north central United States (Bridges and Baumann 1992), an area typically characterized by warm temperatures, high precipitation, and low elevation relative to the rest of the region. Therefore, the negative relationship between GDDs and precipitation and demographic performance of AMBTR are contradictory to hypothesis 3, though the negative relationship with site elevation offers partial support for hypothesis 3 (given that elevation decreased with longitude, from west to east, among sites in this study; $R=0.72$, $P<0.01)$.

Annual precipitation historically increases from west to east in the north central United States; thus, it was hypothesized that AMBTR success and precipitation would be positively related, which is congruent with the historical distribution of this species (Bridges and Baumann 1992). However, there was a negative correlation between annual precipitation and longitude across site-years in this study $(R=-0.54$, $P<0.01)$. The abnormal precipitation patterns across the north central United States between 2006 and 2008 (Table 2) may help to explain the negative relationship between AMBTR demography and precipitation. Induced secondarydormancy or increased fungal decay of AMBTR seeds may have occurred under abnormally wet conditions in the western sites in this study region, contributing to the negative relationship between demography and precipitation (Forcella et al. 1992; Schafer and Kotanen 2003).

Similar to AMBTR, demography of HELAN was most affected by $\mathrm{GDD}_{2}$ as indicated by the first PLS component, which explained $77.0 \%$ of the variation in HELAN demography. The most important environmental predictor variables in the first PLS component, as indicated by the largest latent variable loadings, were annual $\mathrm{GDD}_{2}, \mathrm{GDD}_{2}$ between March and October, and $\mathrm{GDD}_{2}$ during weed growth (from seedling recruitment to reproductive maturity), respectively (Figure 6). In contrast to the results for AMBTR, the direction of this first PLS component for HELAN was positive, indicating a positive relationship between $\mathrm{GDD}_{2}$ and demography. The second PLS component explained only $8.5 \%$ of the variation in HELAN demography and was characterized largely by precipitation and elevation. The most important environmental predictor variables contributing to 


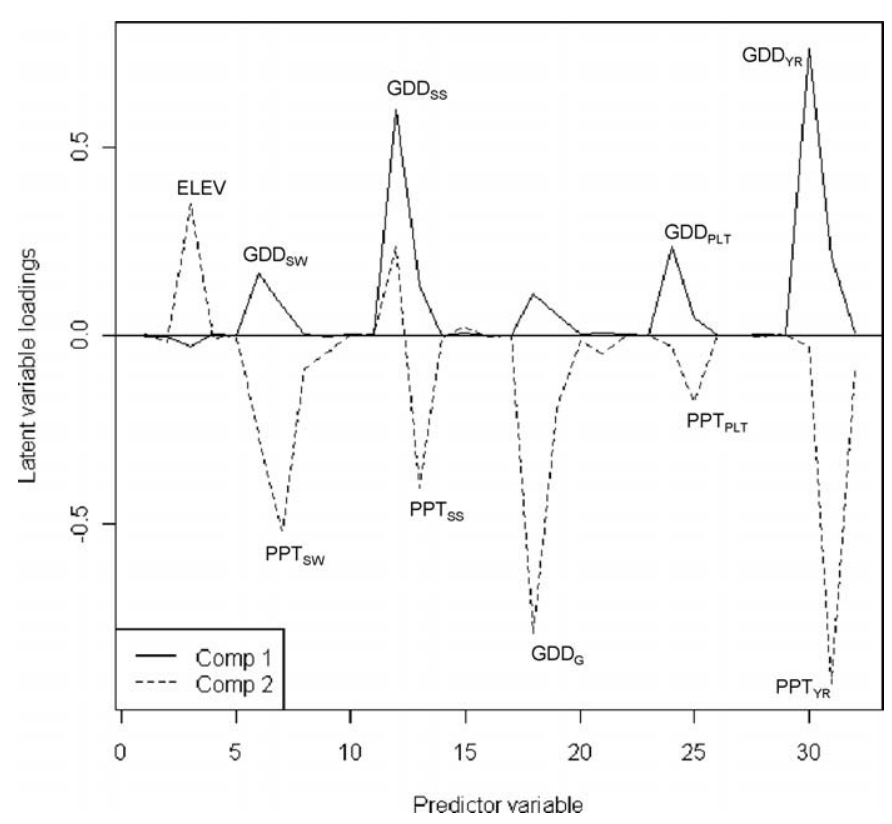

Figure 6. Latent variable loadings for 32 different environmental predictor variables in the partial least squares regression for HELAN demography. The first component explains $77.0 \%$ of the variation in HELAN demography, and the second component explains $8.5 \%$ of the variation. The largest latent variable loadings for each component are labeled in the figure: ELEV = site elevation; $\mathrm{GDD}_{\mathrm{SW}}=$ winter growing degree days base $2 \mathrm{C}$; $\mathrm{PPT}_{\mathrm{SW}}=$ winter precipitation; $\mathrm{GDD}_{\mathrm{SS}}=$ summer growing degree days base $2 \mathrm{C} ; \mathrm{PPT}_{\mathrm{SS}}=$ summer precipitation; $\mathrm{GDD}_{\mathrm{G}}=$ growing degree days base $2 \mathrm{C}$ during seedling recruitment; $\mathrm{GDD}_{\mathrm{PLT}}=$ growing degree days base $2 \mathrm{C}$ during weed growth; $\mathrm{PPT}_{\mathrm{PLT}}=$ precipitation during weed growth; $\mathrm{GDD}_{\mathrm{YR}}=$ annual growing degree days base $2 \mathrm{C}$; and $\mathrm{PPT}_{\mathrm{YR}}=$ annual precipitation.

the second PLS component, as indicated by the largest latent variable loadings, were annual precipitation, $\mathrm{GDD}_{2}$ during seedling recruitment, precipitation between October and March of the previous year, and elevation, respectively (Figure 6). The relationship between HELAN demography and each of these latent variables was negative with the exception of elevation, which was positive. Overall, these results suggest that the demographic performance of HELAN was greatest in warm and dry site-years with a higher site elevation, which is consistent with hypotheses 2 and 3 . Historically, HELAN is most abundant in the southwest portion of the north central United States (Bridges and Baumann 1992), which is an eco-region typically characterized by lower annual precipitation, warmer temperatures, and higher elevation compared to the rest of the north central region.

The relationship between the demography of both AMBTR and HELAN and environmental variation supports the findings of several previous studies on plant distribution and success (e.g., Colautti et al. 2009; Davis et al. 2005; Mack and Pyke 1983; Wang and Gao 2003). However, at least two studies found that precipitation was the most important factor in explaining plant distribution and demographic performance (Mack and Pyke 1983; Wang and Gao 2003), which is not consistent with the results of this study where GDDs (e.g., temperature) accounted for most of the variation in the first PLS component in the analysis of both AMBTR and HELAN. Precipitation did explain most of the variation in the second PLS component for both species, but the total variation in demography explained by the second PLS component was relatively small.
The use of PLSR analysis (a newer multivariate method; Carrascal et al. 2009) corrected for the strong correlation among environmental variables and also among demographic parameters, and provided valuable insight about the important environmental factors driving AMBTR and HELAN demographic performance. Overall, PLSR analysis of this large data set suggests that temperature $\left(\mathrm{GDD}_{2}\right)$ and precipitation explain a substantial portion of the overall demography of both weed species. Despite the apparent influence of competitive environment on late life stage transitions, environmental data was still sufficient to explain more than $80 \%$ of the variation in the overall demography of both weed species using PLSR analysis. This result provides support for the use of bioclimatic and weather-based statistical models in understanding current weed distribution and demography, while also acknowledging the theoretical shortcomings of this and similar models (e.g., the need to account for limiting factors such as resource availability and dispersal mechanisms; Pearson and Dawson 2003).

Projections of climate change include air temperature increases along with changes in the distribution and intensity of rainfall (Meehl et al. 2007). Given the combined importance of temperature and precipitation in explaining the demography of HELAN and AMBTR $(>80 \%$ of the variation explained), these results suggest that these two species will be susceptible to the projected outcomes of global climate change. Congruent with the predictions of Walther et al. (2002), this study suggests that long-term distributional changes for these two species could follow a latitudinal cline consistent with their response to temperature as this was the most influential environmental variable. However, consistent regional spatial trends in demography were not observed in this relatively short-term study despite the importance of local temperature and precipitation. While many factors must be considered in predicting future plant distribution (e.g., resource availability, management, geography, competition, seed dispersal, and topography), the importance of temperature in understanding weed distribution and performance observed in this study is consistent with many previous studies (e.g., Beerling 1993; Chen et al. 2011; Dunlop et al. 2006; Milbau et al. 2009). Future regional studies should strive to bridge the gap between abiotic factors (e.g., temperature and precipitation) and the complex suite of biotic factors (e.g., soil microbial feedback, competition, and seed dispersal) driving the realized distribution and demography of weedy species in a changing global climate.

\section{Acknowledgments}

The authors gratefully acknowledge the many students and technicians at each site who carried out the thorough field work and data collection required for a successful regional research project.

\section{Literature Cited}

Andreasen, C., J. C. Streibig, and H. Haas. 1991. Soil properties affecting the distribution of 37 weed species in Danish fields. Weed Res. 31:181-187.

Bauer, T. A. and D. A. Mortensen. 1992. A comparison of economic and economic optimum thresholds for two annual weeds in soybeans. Weed Technol. 6:228-235.

Baysinger, J. A. and B. D. Sims. 1991. Giant ragweed (Ambrosia trifida L.) interference in soybeans (Glycine max). Weed Sci. 39:358-362.

Wortman et al.: Regional variation in weed demography • 
Beerling, D. J. 1993. The impact of temperature on the northern distribution limits of the introduced species Fallopia japonica and Impatiens glandulifera in North-West Europe. J. Biogeogr. 20:45-53.

Brainard, D. C., R. R. Bellinder, and A. DiTommaso. 2005. Effects of canopy shade on the morphology, phenology, and seed characteristics of powell amaranth (Amaranthus powellii). Weed Sci. 53:175-186.

Bridges, D. C. and P. A. Baumann. 1992. Weeds causing losses in the United States. Pages 75-147 in D. C. Bridges, ed. Crop Losses due to Weeds in the United States. Champaign, IL: Weed Science Society of America.

Burton, M. G., D. A. Mortensen, and D. B. Marx. 2005. Environmental characteristics affecting Helianthus annuus distribution in a maize production system. Agr. Ecosyst. Environ. 111:30-40.

Burton, M. G., D. A. Mortensen, D. B. Marx, and J. L. Lindquist. 2004. Factors affecting the realized niche of common sunflower (Helianthus annuus) in ridgetillage corn. Weed Sci. 52:779-787.

Byers, D. L. and J. A. Quinn. 1998. Demographic variation in Alliaria petiolata (Brassicaceae) in four contrasting habitats. J. Torrey Bot. Soc. 125:138-149.

Carrascal, L. M., I. Galván, and O. Gordo. 2009. Partial least squares regression as an alternative to current regression methods used in ecology. Oikos 118:681-690.

Chen, I-C., J. K. Hill, R. Ohlemüller, D. B. Roy, and C. D. Thomas. 2011 Rapid range shifts of species associated with high levels of climate warming. Science 333:1024-1026.

Colautti, R. I., J. L. Maron, and S.C.H. Barrett. 2009. Common garden comparisons of native and introduced plant populations: latitudinal clines can obscure evolutionary inferences. Evol. Appl. 2:187-199.

Cousens, R. and M. Mortimer. 1995. Dynamics of Weed Populations. New York: Cambridge University Press. Pp. 86-216.

Dale, M.R.T., A. G. Thomas, and E. A. John. 1992. Environmental factors including management practices as correlates of weed community composition in spring seeded crops. Can. J. Bot. 70:1931-1939.

Davis, A. S. 2006. When does it make sense to target the weed seed bank? Weed Sci. 54:558-565.

Davis, A. S., J. Cardina, F. Forcella, G. A. Johnson, G. Kegode, J. L. Lindquist, E. C. Luschei, K. A. Renner, C. L. Sprague, and M. M. Williams, II. 2005. Environmental factors affecting seed persistence of annual weeds across the U.S. corn belt. Weed Sci. 53:860-868.

Davis, A. S., P. M. Dixon, and M. Liebman. 2004. Using matrix models to determine cropping system effects on annual weed demography. Ecol. Appl. 14:655-668.

Diaz, S., M. Cabido, and F. Casanoves. 1998. Plant functional traits and environmental filters at a regional scale. J. Veg. Sci. 9:113-122.

Dieleman, J. A., D. A. Mortensen, D. D. Buhler, C. A. Cambardella, and T. B. Moorman. 2000a. Identifying associations among site properties and weed species abundance. I. Multivariate analysis. Weed Sci. 48:567-575.

Dieleman, J. A., D. A. Mortensen, D. D. Buhler, and R. B. Ferguson. 2000b. Identifying associations among site properties and weed species abundance. II. Hypothesis generation. Weed Sci. 48:576-587.

Dunlop, E. A., J. C. Wilson, and A. P. Mackey. 2006. The potential geographic distribution of the invasive weed Senna obtusifolia in Australia. Weed Res. 46:404-413.

Ehleringer, J. R. 1988. Changes in leaf characteristics of species along elevational gradients in the Wasatch Front Utah USA. Am. J. Bot. 75:680-689.

Forcella, F. 1992. Prediction of weed seedling densities from buried seed reserves. Weed Res. 32:29-38.

Forcella, F., R. G. Wilson, J. Dekker, R. J. Kremer, J. Cardina, R. L. Anderson, D. Alm, K. A. Renner, R. G. Harvey, S. Clay, and D. D. Buhler. 1997. Weed seed bank emergence across the corn belt. Weed Sci. 45:67-76.

Forcella, F., R. G. Wilson, K. A. Renner, J. Dekker, R. G. Harvey, D. A. Alm, D. D. Buhler, and J. A. Cardina. 1992. Weed seedbanks of the U.S. cornbelt: magnitude, variation, emergence, and application. Weed Sci. 40:636-644.

Gaston, K. J. 2009. Geographic range limits: achieving synthesis. Proc. R. Soc. Lond. B. 276:1395-1406.

Gotelli, N. J. and A. M. Ellison. 2004. A Primer of Ecological Statistics. Sunderland, MA: Sinauer. 150 p.

Grundy, A. C., A. Mead, S. Burston, and T. Overs. 2004. Seed production of Chenopodium album in competition with field vegetables. Weed Res. 44:271-281.

Harrison, S. K., E. E. Regnier, J. T. Schmoll, and J. M. Harrison. 2007. Seed size and burial effects on giant ragweed (Ambrosia trifida) emergence and seed demise. Weed Sci. 55:16-22.

Harrison, S. K., E. E. Regnier, J. T. Schmoll, and J. E. Webb. 2001. Competition and fecundity of giant ragweed in corn. Weed Sci. 49:224-229.

High Plains Regional Climate Center. 2012. Climate Information for Management and Operational Decisions. http://climod.unl.edu/. Accessed: March 21, 2012.

Hogg, R. V. and A. T. Craig. 1995. Introduction to Mathematical Statistics, 5th ed. Englewood Hall, NJ: Prentice Hall. Pp. 251-252.
Hopkins, A. D. 1919. Periodical Events and Natural Law as Guides to Agricultural Research and Practice. Supplement 9. Washington, DC: U.S. Bureau of Entomology.

Horvitz, C. C. and D. W. Schemske. 1995. Spatiotemporal variation in demographic transitions for a neotropical understory herb: projection matrix analysis. Ecol. Monogr. 65:155-192.

Jordan, N. 1993. Simulation analysis of weed population dynamics in ridge-tilled fields. Weed Science 41:468-474.

Joshi, J., B. Schmid, M. C. Caldeira, P. G. Dimitrakopoulos, J. Good, R. Harris, A. Hector, K. Huss-Danell, A. Jumpponen, A. Minns, C.P.H. Mulder, J. S Pereira, A. Prinz, M. Scherer-Lorenzen, A.S.D. Siamantziouras, A. C. Terry, A. Y. Troumbis, and J. H. Lawton. 2001. Local adaptation enhances performance of common plant species. Ecol. Lett. 4:536-544.

Keddy, P. A. 1992. Assembly and response rules: two goals for predictive community ecology. J. Veg. Sci. 3:157-164.

Keller, S. R., D. R. Sowell, M. Neiman, L. M. Wolfe, and D. R. Taylor. 1999. Adaptation and colonization history affect the evolution of clines in two introduced species. New Phytol. 183:678-690.

Mack, R. N. and D. A. Pyke. 1983. The demography of Bromus tectorum: variation in time and space. J. Ecol. 71:69-93.

Meehl, G. A., T. F. Stocker, W. D. Collins, P. Friedlingstein, A. T. Gaye, J. M. Gregory, A. Kitoh, R. Knutti, J. M. Murphy, A. Noda, S.C.B. Raper, I. G. Watterson, A. J. Weaver, and Z. C. Zhao. 2007. Global climate projections. In S. Solomon, D. Qin, M. Manning, Z. Chen, M. Marquis, K. B. Averyt, M. Tignor, and H. L. Miller, eds. Climate Change 2007: The Physical Science Basis. Contribution of Working Group I to the Fourth Assessment Report of the Intergovernmental Panel on Climate Change. Cambridge, United Kingdom, and New York: Cambridge University Press. Pp. 749-844.

Milbau, A., B. J. Graae, A. Shevtsova, and I. Nijs. 2009. Effects of a warmer climate on seed germination in the subarctic. Ann. Bot. 104:287-296.

National Oceanic and Atmospheric Administration. 2012. Earth Systems Research Laboratory, Physical Sciences Division. http://www.esrl.noaa.gov/ psd/data/usclimdivs/index.html. Accessed: March 21, 2012.

Pearson, R. G. and T. P. Dawson. 2003. Predicting the impacts of climate change on the distribution of species: are bioclimate envelope models useful? Global Ecol. Biogeogr. 12:361-371.

Pearson, R. G., T. P. Dawson, P. M. Berry, and P. A. Harrison. 2002. SPECIES a spatial evaluation of climate impact on the envelope of species. Ecol. Model. 154:289-300.

Peters, J., ed. 2000. Tetrazolium Testing Handbook. Contribution No. 29 to the Handbook on Seed Testing. Lincoln, NE: Association of Official Seed Analysts. Pp. 1-18, 151-154.

Santamaria, L., J. Figuerola, J. J. Pilon, M. Mjelde, A. J. Green, T. De Boer, R. A. King, and R. J. Gornall. 2003. Plant performance across latitude: the role of plasticity and local adaptation in an aquatic plant. Ecology 84:2454-2461.

Savolainen, O., T. Pyhajarvi, and T. Knurr. 2007. Gene flow and local adaptation in trees. Annu. Rev. Ecol. Evol. S. 38:595-619.

Schafer, M. and P. M. Kotanen. 2003. The influence of soil moisture on losses of buried seeds to fungi. Acta Oecol. 24:255-263.

Schutte, B. J., E. E. Regnier, S. K. Harrison, J. T. Schmoll, K. Spokas, and F. Forcella. 2008. A hydrothermal seedling emergence model for giant ragweed (Ambrosia trifida). Weed Sci. 56:555-560.

Snow, A. A., D. Pilson, L. H. Rieseberg, M. J. Paulsen, N. Pleskac, M. R. Reagon, D. E. Wolf, and S. M. Selbo. 2003. A Bt transgene reduces herbivory and enhances fecundity in wild sunflowers. Ecol. Appl. 13:279-286.

Thuiller, W. 2003. BIOMOD-optimizing predictions of species distributions and projecting potential future shifts under global change. Global Change Biol. 9:1353-1362.

Walther, G., E. Post, P. Convey, A. Menzel, C. Parmesan, T.J.C. Beebee, J. Fromentin, O. Hoegh-Guldberg, and F. Bairlein. 2002. Ecological responses to recent climate change. Nature 416:389-395.

Wang, R. and Q. Gao. 2003. Climate-driven changes in shoot density and shoot biomass in Leymus chinensis (Poaceae) on the North-east China Transect (NECT). Global Ecol. Biogeogr. 12:249-259.

Wiles, L. J., D. H. Barlin, E. E. Schweizer, H. R. Duke, and D. E. Whitt. 1996 A new soil sampler and elutriator for collecting and extracting weed seeds from soil. Weed Technol. 10:35-41.

Woodward, F. I. 1987. Climate and plant distribution. Cambridge, United Kingdom: Cambridge University Press. 174 p.

Wortman, S. E., A. S. Davis, B. J. Schutte, and J. L. Lindquist. 2011. Integrating management of soil nitrogen and weeds. Weed Sci. 59:162-170.

Received November 22, 2011, and approved March 26, 2012. 